\title{
Possible degradation of chlorophyll-derived pigments during gut passage of herbivorous copepods
}

\author{
A. F. Pasternak, A. V. Drits \\ Institute of Oceanology, Academy of Science USSR, 117218 Krasikova 23, Moscow, USSR
}

\begin{abstract}
Dynamics of total amounts of chlorophyllderived pigments during gut passage in 3 copepod species (Calanus pacificus, Undinula darwini, Pleuromamma sp.), fed Phaeodactylum tricornutum as well as natural food, were studied in 3 series of experiments. A decrease in fluorescence of ingested pigments did not occur within the time span from 10 min after commencement of feeding until the first defaecation. The total amount of pigments in the gut and in faecal pellets 1 to $2 \mathrm{~h}$ after transfer of prefed copepods into filtered seawater was, on average, equal to the initial gut pigment content at the moment of copepod transfer. We conclude that chlorophyll-derived pigments are not substantially destroyed during passage through the guts of herbivorous copepods, irrespective of the initial chlorophyll concentration.
\end{abstract}

One of the most widely used methods for estimating in situ algal grazing rates of zooplankton is gut fluorescence. The methodological problems of this approach were reviewed in detail by Kiørboe \& Tiselius (1987). The method is based on the assumption that chlorophyll and its derivatives are not degraded to nonfluorescent compounds during digestion (Mackas \& Bohrer 1976). However, experiments carried out by Conover et al. (1986) showed that chlorophyll-derived pigments may be partly destroyed or digested in the gut. This conclusion was based on comparison of pigments and biogenic silica content between food ingested by copepods and faecal pellets. The silica content of faecal pellets equalled more than $80 \%$, but pigments only 0.1 to $8 \%$, of the amounts ingested. These results were obtained from prolonged experiments; faecal pellets were held in experimental vessels for up to $48 \mathrm{~h}$, while gut passage time was only about $1 \mathrm{~h}$. It is unknown whether the loss of pigments occurs in the gut or in faecal pellets. The present work was designed to estimate the level of pigment destruction directly in the gut of copepods.

Methods. Experiments were carried out on board RV 'Dm. Mendeleev' during Cruise 38 in the Californian region and tropical Pacific. Experimental animals (mainly adult females of Calanus pacificus, but also of Undinula darwini and Pleuromamma sp.) were captured by vertical tows from 0 to $70 \mathrm{~m}$ water depth with a BR-plankton net $(113 \mathrm{~cm}$ diameter closing net with $550 \mu \mathrm{m}$ mesh). C. pacificus were captured at Station $3529\left(29^{\circ} 29^{\prime} \mathrm{N}, 115^{\circ} 44^{\prime} \mathrm{W}\right)$, U. darwini at Station 3452 $\left(7^{\circ} 41^{\prime} \mathrm{N}, 15^{\circ} 23^{\prime} \mathrm{W}\right)$, and Pleuromamma sp. at Station $3453\left(6^{\circ} 58^{\prime} \mathrm{N}, 135^{\circ} 58^{\prime} \mathrm{W}\right)$. We used 3 experimental designs.

In the first experiment, copepods were kept for $24 \mathrm{~h}$ in filtered seawater, then placed into five $200 \mathrm{ml}$ experimental vessels (15 ind. vessel ${ }^{-1}$ ) to which the diatom Phaeodactylum tricornutum was added $1.0 \mathrm{ng}$ Chl $\left.\mathrm{ml}^{-1}\right)$. Each experimental vessel consisted of 2 plastic glasses placed one into another, with the bottom of the inner one made of $550 \mu \mathrm{m}$ mesh plankton gauze. Ten min after adding the food, Calanus pacificus from the first vessel were narcotized with carbon dioxide and used for fluorescence analysis. One replicate consisted of 5 individuals. Simultaneously, copepods from parallel vessels were transferred to filtered seawater. Following transfer, copepods from the 2 nd vessel were narcotized after $5 \mathrm{~min}$; from the $3 \mathrm{rd}$, after $10 \mathrm{~min}$; from the 4 th, after $20 \mathrm{~min}$; from the 5 th, after $40 \mathrm{~min}$.

The second experiment was similar, with 2 exceptions: (1) copepods, transferred to 3 experimental vessels with filtered seawater, were narcotized 30,60 and 120 min after transfer; (2) faecal pellets were collected and pooled for each experimental vessel and their chlorophyll-related pigments were determined. Experiments were carried out at 2 concentrations of pigments ( 1.3 and $4.8 \mathrm{ng} \mathrm{Chl} \mathrm{ml}^{-1}$ ) to investigate the influence of initial gut fullness on pigment degradation.

The third experiment was designed to estimate pigment degradation in the gut of Calanus pacificus fed a natural suspension. Freshly caught individuals were aggregated in a small volume of water and then carefully placed, using tweezers, into $150 \mathrm{ml}$ experimental 
vessels (5 ind. vessel $\left.{ }^{-1}\right)$ with filtered $(1 \mu \mathrm{m})$ seawater. The process of aggregation and transfer took less than 3 to $5 \mathrm{~min}$. After the end of transfer, copepods from the first 3 vessels were narcotized. Individuals from each vessel constituted 1 replicate. Copepods from the next 5 vessels were narcotized after $30 \mathrm{~min}$, those from the last 5 vessels, $60 \mathrm{~min}$ after transfer. Simultaneously, faecal pellets were picked up in every experimental vessel. A similar scheme was followed in the experiments with the tropical copepods Pleuromamma sp. and Undinula darwini. All experiments were carried out in dim light.

Experiments with Calanus pacificus were carried out at 13 to $14{ }^{\circ} \mathrm{C}$; experiments with tropical copepods, at 23 to $24^{\circ} \mathrm{C}$, corresponding to the mean temperatures of the water inhabited by them. At the end of the experiments narcotized copepods and faecal pellets were ground in a tissue-grinder (RT-2) in a small volume of $90 \%$ acetone. Plant pigments were extracted over 4 to $8 \mathrm{~h}$ in 1 to $3 \mathrm{ml}$ of $90 \%$ acetone. The quantity of chlorophyll-derived pigments was measured with laser fluorimetry (Fadeev et al. 1980). This method permits the measurement of concentrations as low as 0.01 to $0.02 \mathrm{ng}$ pigm. $\mathrm{ml}^{-1}$ (in the extract).

Results and Discussion. Results obtained in the first experiment are given in Table 1 . The quantity of plant

Table 1. Calanus pacificus. Dynamics of chlorophyll-derived pigments in the gut (1st experiment, 23 Mar 1987), S(Chl+ph): gut pigments (ng ind. ${ }^{-1}$ ); $t$ : time of copepod maintenance in filtered water In parentheses: number of replicates

\begin{tabular}{|cc|}
\hline $\mathrm{t}$ & $\begin{array}{c}\mathrm{S}_{(\mathrm{Chl}+\mathrm{Ph})} \\
\text { Mean } \pm \mathrm{SD}\end{array}$ \\
\hline 0 & $0.23 \pm 0.04(3)$ \\
5 & $0.18 \pm 0.06(3)$ \\
10 & $0.23 \pm 0.05(3)$ \\
20 & $0.18 \pm 0.06(3)$ \\
40 & $0.04 \pm 0.03(3)$ \\
\hline
\end{tabular}

pigments in the gut of Calanus pacificus was practically constant during the initial 20 min after transfer into filtered water. After $40 \mathrm{~min}$, the quantity of chlorophyll-derived pigments $\mathrm{S}_{(\mathrm{Ch})+\mathrm{Ph})}$ decreased dramatically; this was related to the first defecation. This experiment indicates that chlorophyll-derived pigments were not significantly destroyed during the passage through the gut of $C$. pacificus.

In the second experiment the quantity of pigments in the guts decreased 30 min after copepod transfer to filtered water, and after 60 min constituted on average $20 \%$ of the initial level (Table 2). Simultaneously $\mathrm{S}_{(\mathrm{Chl}+\mathrm{ph})}$ in faecal pellets increased. The sum of pigments in gut and faecal pellets decreased by $40 \%$ in $2 \mathrm{~h}$ in the experiment with a food concentration of $4.8 \mu \mathrm{g}$ pigm. $\mathrm{l}^{-1}$. Unfortunately, we are unable to carry out statistical analyses of the results obtained in this experiment because the faecal pellets were pooled. At the lower food level the sum of pigments in gut and in faecal pellets remained practically unchanged. According to Conover et al. (1986) the fraction of pigment recovered is positively correlated with the amount ingested'. Out data show however that a lower initial level of $\mathrm{S}_{(\mathrm{Ch}+\mathrm{Ph})}$ does not lead to a significant destruction of chlorophyll and phaeopigments in the gut of copepods. Note that the feeding activities of copepods in the first experiment were not high (low level of $\left.\mathrm{S}_{(\mathrm{Chl}+\mathrm{Ph})}\right)$.

In the experiment with Calanus pacificus females feeding on natural particulate matter we also did not find significant decrease of plant pigments in gut and faecal pellets (ANOVA, $F<F_{0.05}[2,10]$; Table 3 ), even though their feeding activities were several times less than the maximum observed for them in that region (about $20 \mathrm{ng}$ pigm. ind ${ }^{-1}$ ). Similar results were obtained in experiments with females of Pleuromamma sp. and Undinula darwini (Tables 4 and 5). With Pleuromamma sp. the sum of pigments in guts and faecal pellets was reduced in $60 \mathrm{~min}$ by 30 to $40 \%$ on average, but

Table 2. Calanus pacificus. Dynamics of chlorophyll-derived pigments in the gut and faecal pellets (2nd experiment, 23 Mar 1987). $\mathrm{S}_{(\mathrm{f})+\mathrm{Ph})}$ f faecal pellet pigments; other symbols as in Table 1

\begin{tabular}{|c|c|c|c|c|c|c|}
\hline \multirow[b]{3}{*}{$\begin{array}{l}\mathrm{t} \\
(\min )\end{array}$} & \multicolumn{6}{|c|}{ Chlorophyll concentration in experiment } \\
\hline & \multicolumn{3}{|c|}{$4.8 \mathrm{ng} \mathrm{ml}^{-1}$} & \multicolumn{3}{|c|}{$1.3 \mathrm{ng} \mathrm{ml}^{-1}$} \\
\hline & $\begin{array}{c}S_{(\mathrm{Chi}+\mathrm{Ph})} \\
\text { Mean } \pm \mathrm{SD}\end{array}$ & $\mathrm{S}_{|\mathrm{Chl}+\mathrm{Ph}|}$ & $S+S^{i}$ & $\begin{array}{c}S_{(C h i+P h)} \\
\text { Mean } \pm S D\end{array}$ & $\mathrm{~S}_{(\mathrm{Ch}+\mathrm{Ph})}$ & $S+S^{f}$ \\
\hline 0 & $1.17 \pm 0.15$ & & & $0.23 \pm 0.04$ & & \\
\hline 30 & $\begin{array}{c}0.77 \pm 0.17 \\
\text { (3) }\end{array}$ & 0.13 & 0.90 & $0.07 \pm 0.04$ & 0.21 & 0.28 \\
\hline 60 & $0.21 \pm 0.16$ & 0.53 & 0.74 & $0.04 \pm 0.03$ & 0.24 & 0.28 \\
\hline 120 & $\begin{array}{c}0.04 \pm 0.02 \\
\text { (3) }\end{array}$ & 0.67 & 0.71 & 0.01 & 0.25 & 0.26 \\
\hline
\end{tabular}


Table 3. Calanus pacificus. Dynamics of chlorophyll-derived pigments in gut and faecal pellets of individuals fed natural food (3rd experiment, 22 Mar 1987). Symbols as in Tables 1 and 2

\begin{tabular}{|cccc|}
\hline $\begin{array}{l}\mathrm{t} \\
(\mathrm{min})\end{array}$ & $\begin{array}{c}\mathrm{S}_{(\mathrm{Chl}+\mathrm{Ph})} \\
\text { Mean } \pm \mathrm{SD}\end{array}$ & $\begin{array}{c}\left.\mathrm{S}^{\mathrm{i}}(\mathrm{Ch})+\mathrm{Ph}\right) \\
\text { Mean } \pm \mathrm{SD}\end{array}$ & $\begin{array}{c}\mathrm{S}+\mathrm{S}^{i} \\
\text { Mean } \pm \mathrm{SD}\end{array}$ \\
\hline 0 & $1.73 \pm 0.87$ & & \\
& $(3)$ & & \\
30 & $0.31 \pm 0.17$ & $1.89 \pm 0.29$ & $2.20 \pm 0.33$ \\
& $(5)$ & $(5)$ & $(5)$ \\
60 & $0.10 \pm 0.11$ & $1.56 \pm 0.39$ & $1.66 \pm 0.40$ \\
& $(5)$ & $(5)$ & $(5)$ \\
\hline
\end{tabular}

Table 4. Undinula darwini. Dynamics of chlorophyll-derived pigments in gut and faecal pellets (15 Jan 1987). Symbols as in Tables 1 and 2

\begin{tabular}{|cccc|}
\hline $\mathrm{t}$ & $\mathrm{S}_{(\mathrm{Chl}+\mathrm{Ph})}$ & $\mathrm{S}^{\mathrm{i}}(\mathrm{Cl}+\mathrm{Ph})$ & $\mathrm{S}+\mathrm{S}^{\mathrm{f}}$ \\
$(\mathrm{min})$ & Mean $\pm \mathrm{SD}$ & Mean $\pm \mathrm{SD}$ & Mean $\pm \mathrm{SD}$ \\
\hline 0 & $0.51 \pm 0.05$ & & \\
& $(3)$ & & \\
60 & $0.24 \pm 0.07$ & $0.33 \pm 0.07$ & $0.57 \pm 0.10$ \\
& $(3)$ & $(3)$ & $(3)$ \\
\hline
\end{tabular}

statistical analysis showed that this difference was not significant $\left(t<t_{0.05}, n=4\right.$, Student's $t$-test).

The results of these experiments suggest that the fluorescence of chlorophyll $a$ and its derivatives is not significantly reduced by the digestive process of copepods. Thus our data did not confirm the results obtained by Conover et al. (1986) (pigment loss up to $99 \%$, provided that pigment destruction was not instantaneous during foregut filling. However, experiments conducted by Dagg \& Walser (1987) and by Kiørboe \& Tiselius (1987), who 'balanced' the pigment budget, suggest that instantaneous destruction was probably not great if it occured. These authors found that the loss of pigment was 10 to $11 \%$ on average and was independent of the amount of food ingested; our results are very similar. Moreover chlorophyll a sometimes made up $100 \%$ in the guts of copepods fed natural suspension (Kleppel \& Pieper 1984) suggesting that instantaneous destruction was hardly possible. In any case the instantaneous destruction which we could not measure in our experiments could not have caused dramatic losses of pigment fluorescence in the gut and thus alter essentially our conclusion.

Kiørboe \& Tiselius (1987) note that 'the analysis of even slightly fragmented faeces dramatically increased the apparent destruction efficiency'. Fluorescent microscopic observation of fresh Calanus pacificus faecal pellets from our experiments showed the presence of a considerable amount of living bacteria inside them

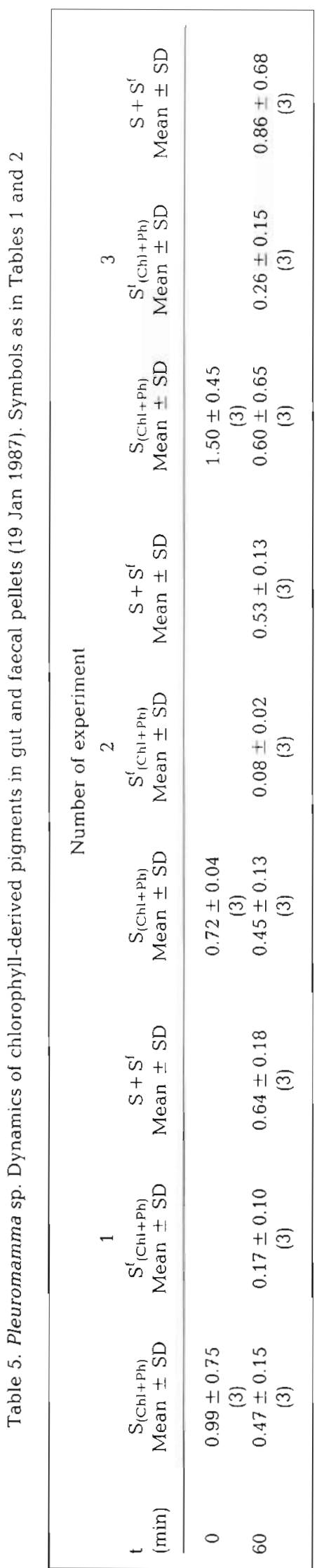


(Tumantseva N. I., pers. comm.). Considerable amounts of living bacteria in newly defecated faeces were found by Gowing \& Silver (1983) who observed rapid bacterial reproduction and biomass increase (by a factor of 3 within 48 h). Perhaps, bacterial activities can cause fragmentation and/or loss of fluorescence in faecal pellets in the course of prolonged storage in experimental containers.

\section{LITERATURE CITED}

Conover, R. J., Durvasula, R., Roy, S., Wang, R. (1986). Probable loss of chlorophyll-derived pigments during passage through the gut of zooplankton, and some of the consequences. Limnol. Oceanogr. 31. 878-886

Dagg, M. J., Walser, W. E. Jr (1987). Ingestion, gut passage, and egestion by the copepod Neocalanus plumchrus in the laboratory and in the subarctic Pacific Ocean. Limnol. Oceanogr. 32: 178-188

Fadeev, V V., Demidov, A. A., Klishko, D. N., KoblensMishke, O. I., Fortus, V M. (1980). The use of laser spectroscope for determination of pigments in the sea phytoplankton. Trans. Inst. Ocean. Acad. Sci. USSR 90: 219-235

Gowing, M. M., Silver, M. W. (1983). Origins and microenvironments of bacteria mediating faecal pellets decomposition in the sea. Mar. Biol. 73: 7-16

Kierboe, T., Tiselius, P. I (1987). Gut clearance and pigment destruction in herbivorous copepod, Acartia tonsa, and the determination of in situ grazing rates. J. Plankton Res. 9: $525-534$

Kleppel, G. S., Pieper, R. E. (1984). Phytoplankton pigments in the gut contents of planktonic copepods from coastal waters of southern California. Mar. Biol. 78: 193-199

Mackas, D., Bohrer, R. (1976). Fluorescence analysis of zooplankton gut contents and an investigation of diel feeding patterns. J. exp. mar. Biol. Ecol. 25: 77-85

This note was submitted to the editor; it was accepted for printing on July 4, 1988 